\title{
Articles
}

\section{Self-Reported and Reported Injury Patterns in Contemporary Dance Students}

\author{
Jo Baker, MSc, Daniel Scott, MSc, Katherine Watkins, MCSP, Sheramy Keegan-Turcotte, MSc, \\ Matthew Wyon, PhD
}

\begin{abstract}
Background: Injury is a major concern among dancers, as currently rates are reported as being high. The purpose of the present study was to assess the incidence and details of injuries across an academic year at a full-time contemporary dance school. Methods: A questionnaire was distributed to 57 dancers at the end of their first academic year. Reported injury information was also retrieved from a database as collected from a physiotherapist over the same period. Results: Differences were found between the reported and selfreported information, particularly with reference to shin injuries. The majority of injuries occurred in November and May, noted to be close to assessment periods. Conclusion: Injury rates in contemporary dance are high; notably, $89 \%$ of dancers reported one or more injuries. This problem is particularly evident in the lower limb. Med Probl Perform Art 2010; 25:10-15.
\end{abstract}

A ccording to Conti and Wong, ${ }^{1}$ if dance movements were properly performed with the correct technique, injuries would rarely occur. Nevertheless, other research has suggested that injuries occur due to the extreme nature of ballet movements and that improper technique increases the injury incidence further. ${ }^{2}$ Injuries have been attributed to the box office demanding "more, faster, and better tricks." ${ }^{3}$ Unfortunately, previous views on injury in dance have disregarded the health of the dancer: "Dancers should not complain about such things and if they are not ready to sacrifice their health to the wonderful art, they should not be dancers." 4

Literature has identified that the most common acute injury with the most reported traumatic injury in dance to be a lateral ankle sprain. ${ }^{1,5}$ Nontraumatic, chronic injuries are more common in dance, ${ }^{6}$ with the literature reporting the most common chronic injury generally occurring in the lower limb. ${ }^{7}$ Washington ${ }^{7}$ made specific reference to anterior compartment syndrome, more commonly known as shin splints. It is possible that, as this syndrome is well known in the domain and frequently documented, dancers are quick to self-diagnose and report this as an injury when they have pain in the lower leg.

Jo Baker is at Laban, London, and London Metropolitan University, London; Daniel Scott is at Kingston University, Kingston upon Thames; Katherine Watkins and Sheramy Keegan-Turcotte are at Laban, London; and Dr. Wyon is at Wolverhampton University, Wolverhampton, UK.

Address correspondence to: Ms. Jo Baker, 166-200 Holloway Rd., London N7 8DB, UK. Tel+44(0) 7734858 997. Joanna.baker@londonmet.ac.uk.
This assumption was supported by Lawson, ${ }^{8}$ who in an article in the Dancing Times, found the 'lower leg' to be the most common self-reported injury (although shin splints were not provided as an option for the reported data, which would have been useful). This article in the Dancing Times highlighted the epidemic of shin splints ${ }^{8}$ and how it was often evident in dancers who had been instructed to force their feet to $180^{\circ}$, regardless of the available external rotation at the hip. ${ }^{9}$ Lawson ${ }^{8}$ suggested that this problem was exacerbated when dancers perform on flat, rather than raked, floors. The etiology of shin splints can be suggested as multifactorial due to hard, flat surfaces, the demands of extreme turnout, and the use of thin or nonsoled shoes.

Results from published studies that have collected injury data from dancers are reported in Table 1. Not only have these studies collected information from dancers in different genres and levels of dance, but they also used different methods of data collection. Studies have recorded information as reported from the dancer in a questionnaire, ${ }^{10}$ in an open interview, ${ }^{6}$ or from physicians' notes. ${ }^{8}$ Regardless of the data source, all the results have consistently shown that the majority of injuries in dancers occur at the lower limb. The study by Washington ${ }^{7}$ was the only one obtaining both reported and self-reported injury information from the same group of dancers. However, in this study the reported information was retrieved from the dance instructors, and therefore it is likely that the injury information lacked detail. In Washington's study, there was a large drop in lower limb injuries from $83 \%$ to $58 \%$ when reported injuries were compared to selfreported injuries, respectively. From reviewing all the present literature regarding dance injuries, there appears to be a substantial lack of studies within the contemporary dance field.

The majority of the literature that discussed the incidence of injuries among dancers attributed them to a lack of anatomical turnout and compensations to achieve optimal turnout. ${ }^{2,14,15}$ However, the literature has struggled to substantiate this relationship. Other possible causes of injury include hypermobility, hypomobility, and lack of strength. ${ }^{6}$ External factors may include intensity, frequency, and duration of dance session, floor surface, footwear, collisions, and fatigue. The literature often neglects to mention that the most common predisposing factor is previous injury. 
TABLE 1. Summary of Studies Reporting Injury Rates (\%) in Dancers at Various Parts of the Body

\begin{tabular}{|c|c|c|c|c|c|c|c|c|}
\hline Study & Genre & Lower Limb & $\begin{array}{l}\text { Hip and } \\
\text { Groin }\end{array}$ & Knee & $\begin{array}{l}\text { Lower } \\
\text { Leg }\end{array}$ & $\begin{array}{c}\text { Ankle } \\
\text { and Foot }\end{array}$ & $\begin{array}{c}\text { Lower and } \\
\text { Upper Back }\end{array}$ & $\begin{array}{l}\text { Upper } \\
\text { Limb }\end{array}$ \\
\hline Milan $^{11}$ & Ballet & - & $7-14$ & $14-20$ & $5-8$ & $13-22$ & $10-17$ & $5-15$ \\
\hline Solomon and Micheli ${ }^{13}$ & Modern dance & 69.8 & 11.3 & 20.1 & 7 & 26.6 & 23.2 & 2.2 \\
\hline Nilsson et al. ${ }^{5}$ & Ballet & 71.6 & 3.8 & 11 & 2.8 & 54 & 17.9 & 7.2 \\
\hline Washington $^{8}(\mathrm{R})$ & Various & 83 & 7 & 34 & - & 42 & 8 & 6 \\
\hline
\end{tabular}

The report by Washington ${ }^{8}$ included both reported (R) and self-reported (SR) data.

The previous literature has found a significant relationship between lower back injuries and many other sites of injury. ${ }^{16}$ Conti and Wong $^{1}$ suggested that the cause of injuries could be grouped into four areas: physique, technique, overuse, and accidents, although risk factors would depend on the genre of the dance. ${ }^{17}$ Dance technique classes are controlled environments that are not replicated when a dancer is working with a choreographer in the professional dance world. Injuries are more likely to occur in an uncontrolled environment, and contemporary dance students are more exposed to these types of situations, such as improvisations and choreography classes, than ballet students.

The current study aimed to:

- Report the injury patterns of first-year contemporary dance students in order to identify trends with reference to the types, common body sites, incidence, and monthly frequency.

- Identify trends in differences between reported (by the physiotherapist) and self-reported (by the dancers) injury data.

- Discuss differences in injuries sustained by males and females.

\section{MATERIAL AND METHODS}

\section{Participants}

Fifty-seven dancers (47 females, 10 males), studying in their first year of a bachelor of arts (BA) degree in dance theatre at a leading UK contemporary dance conservatoire, took part in the study. Table 2 outlines the participants' demographic data.

Between October 30, 2006, and June 15, 2007, the firstyear dance students partook in $180 \mathrm{hr}$ of contemporary dance and $144 \mathrm{hr}$ of ballet. For 5 wks prior to this, they took part in fundamental skills training that did not include technique classes.

\section{Procedure}

A questionnaire was developed by the researchers that was adapted from Dance UK's injury questionnaire. ${ }^{16}$ This selfreported questionnaire obtained information regarding injuries sustained between September 2006 and June 2007 and included details for the date of first occurrence, side of the body, site, type, structure damaged, acute or chronic (interpreted by the researcher based on how long the injury was a problem), training days lost, perceived cause, and whether the physiotherapist was visited. For the purposes of the self-reported injuries in the present study, an injury was defined on the questionnaire as "physical damage to the body or body part ${ }^{18}$ which prevented completion of one or more entire curriculum class." In addition, similar factors from clinically reported injury data by the conservatoire's physiotherapist were obtained from Injury Zone, the UK Sport electronic athlete medical record system. This information was retrieved for the 57 dancers who completed questionnaires anonymously via ID numbers.

All students signed an informed consent form and completed the medical Performance Activity Readiness Questionnaire (PAR-Q) with the questionnaire in June 2007. The questionnaire included a statement allowing their Injury Zone information to be retrieved. The study was reviewed and granted ethical approval from the ethics committee of Laban, London.

\section{Data Analysis}

Although 57 dancers were included in the present study, when injuries were grouped by month, site, or cause, the frequency was too low for statistical analysis. Therefore, trends were observed. In addition, the purpose of the study was not to generalize for the greater population but to provide feedback to this particular institution. Therefore, statistical analysis would not be useful in this case. The study design is one that could be used by other institutions or companies for their individual feedback.

\section{RESULTS}

The self-reported injury information identified 75 individual injuries, of which 60 were incurred by females. However, injury details were provided for only 70 of these injuries. The physiotherapist-reported injury information identified 63

TABLE 2. Demographic Information of All Participants

\begin{tabular}{lcr}
\hline & $\begin{array}{c}\text { Female } \\
(n=47)\end{array}$ & \multicolumn{1}{c}{$\begin{array}{c}\text { Male } \\
(n=10)\end{array}$} \\
\hline Height $(\mathrm{m})$ & $1.65 \pm 0.05$ & $1.74 \pm 0.06$ \\
Weight $(\mathrm{kg})$ & $56.23 \pm 6.51$ & $65.50 \pm 9.03$ \\
Age (yrs) & $20.0 \pm 2.51$ & $21.0 \pm 3.00$ \\
\hline
\end{tabular}

Data presented are mean \pm SD. 


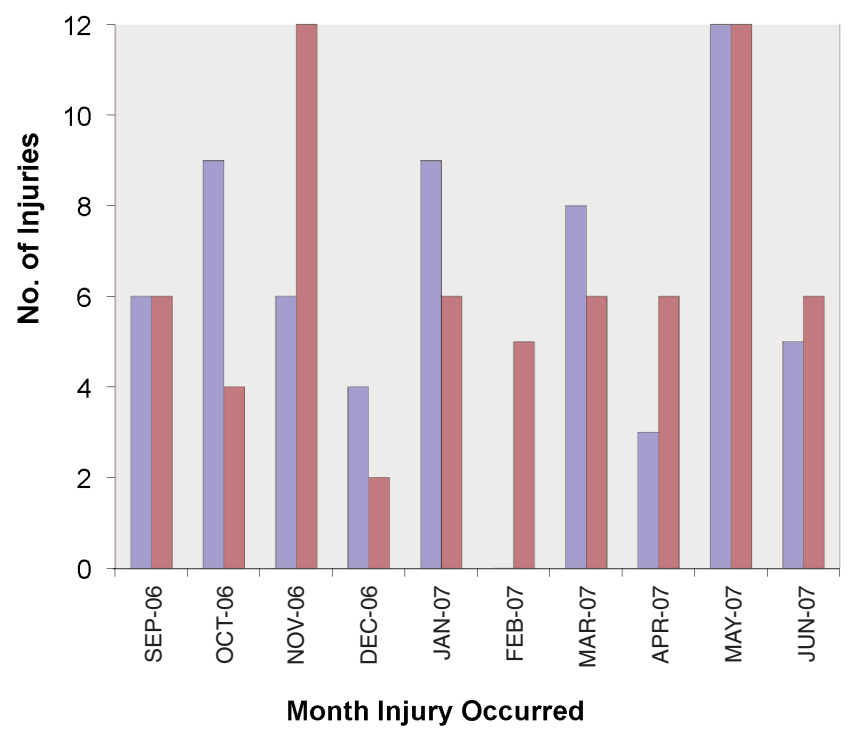

FIGURE 1. Incidence of injuries by month for female and male first-year contemporary dance students during one academic year. The light bars represent self-reported data (by dancers), and the dark bars show reported (physiotherapist) data.

individual injuries, of which 52 were in females. Of the 57 dancers who participated in the present study, $89 \%$ reported 1 or more injuries, by any method.

Figure 1 shows that the month of May had the highest injury rate, with 12 injuries each for self-reported and reported injury information. The reported information also showed the same frequency in November. The self-reported data showed high rates also for October $(n=9)$ and January $(n=9)$ and no injuries for the month of February. The reported injury information found the lowest injury rate, only 2 injuries, in December.

In Figure 2, the self-reported injury information shows the most frequent site injured was the shin and ankle, both reporting $20 \%$ of injuries. This was followed by the knee, with $17.14 \%$ of the injuries. The reported injury information showed the most frequently injured site was the knee $(20.63 \%)$, followed by the ankle (17.46\%). The greatest difference between self-reported and reported injuries was observed at the shin, with $20 \%$ by self-reported means compared to only $9.52 \%$ by reported means. All of the shin injuries that were self-reported were categorized specifically as shin splint syndrome. Both self-reported and reported data showed the thigh and foot were equally the least common site to be injured. When all lower limb injures were totalled, 73\% were found by the reported information and $79 \%$ by the selfreported.

In Table 3, self-report data show that males reported no foot injuries and a much greater percentage of lower back injuries, $21.4 \%$, than females, $5.4 \%$. The males had an equal percentage of upper body, hip/groin, knee, shin, and ankle injuries. The reported injury information in Table 3 also showed no foot or thigh injuries in the males. Lower back injuries accounted for only $9.1 \%$ of male injuries compared to $15.4 \%$ of female injuries. In addition, $36.4 \%$ of the reported injuries incurred by males were of the upper body, compared to only $14.3 \%$ that were self-reported.

Figure 3 shows that the most common perceived cause of injury was jumping, followed by overuse. All of the injuries that were categorized as shin splints mentioned either jumping or overuse as the perceived cause.

The most common self-reported and reported structure damaged was "muscle," followed by "ligament" (self-reported) and "joint" (reported). The most common self-reported and reported type of injury was "inflammation," followed by "strain/sprain/rupture." The reported data, collected by Injury Zone, had gaps in the data. For "structure damaged," $27 \%$ of the injuries were marked "undiagnosed"; for the "occurrence of injury," 52\% of the injuries were "not reported"; and for the "place of occurrence," $86 \%$ were "not reported." The other factors from the questionnaire-side of body, number of training days off, and whether the physiotherapist was visited-were disregarded by many participants and therefore omitted from the discussion.

\section{DISCUSSION}

The majority of injuries occurred in November and May, both with 12 injuries reported. For November, this figure was obtained by the reported injuries, compared to only 6 selfreported injuries. In May, this figure $(n=12)$ was obtained by both reported and self-reported injuries. The increase in students presenting to the physiotherapist may be due to preChristmas assessments or minor injuries that the participants did not feel "important" enough to self-report but at the time they wanted to take advantage of the available physiotherapist before Christmas holidays. It is also important to highlight that first-year students do not commence technique classes until October 15, and therefore this may account for the surge in injuries in November, as they are unable to cope

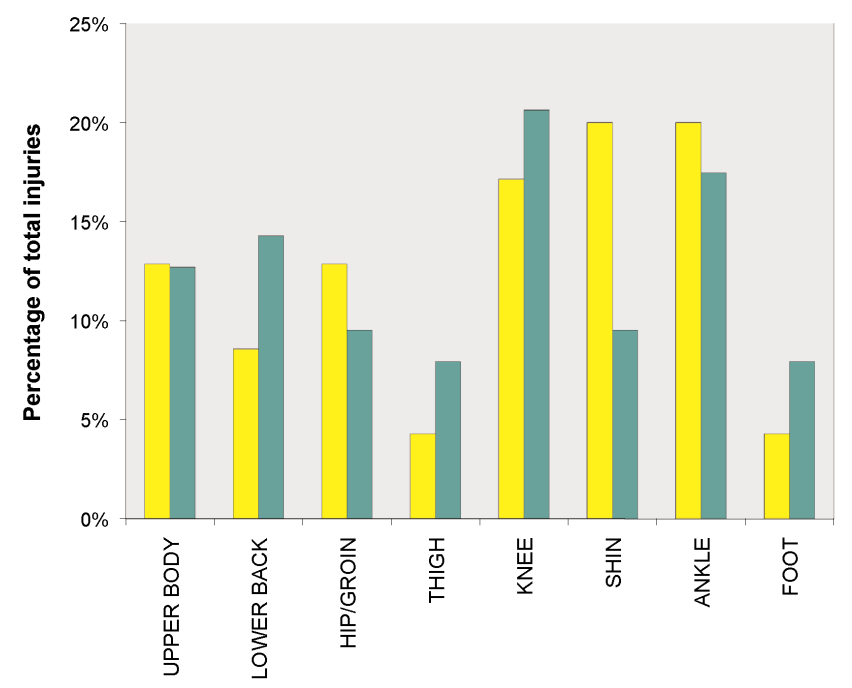

FIGURE 2. Injury sites recorded for first-year female contemporary dance students for the academic year 2006-07. The light bars represent self-reported data (by dancers), and the dark bars show reported data (by physiotherapists). 
TABLE 3. Self-Reported and Reported Injury Sites in First-Year Contemporary Dancers

\begin{tabular}{|c|c|c|c|c|}
\hline Site & \multicolumn{2}{|c|}{ Self-Reported Injuries } & \multicolumn{2}{|c|}{ Reported Injuries } \\
\hline Upper body & $12.5 \% \quad(7)$ & $14.3 \% \quad(2)$ & $7.7 \% \quad(4)$ & $36.4 \% \quad(4)$ \\
\hline Hip/groin & $12.5 \% \quad(7)$ & $14.3 \% \quad(2)$ & $9.6 \% \quad(5)$ & $9.1 \% \quad(1)$ \\
\hline Thigh & $3.6 \% \quad(2)$ & $7.1 \% \quad(1)$ & $9.6 \% \quad(5)$ & $0 \% \quad(0)$ \\
\hline Ankle & $21.4 \%(12)$ & $14.3 \% \quad(2)$ & $17.3 \% \quad(9)$ & $18.2 \% \quad(2)$ \\
\hline Foot & $5.4 \% \quad(3)$ & $0.0 \% \quad(0)$ & $9.6 \% \quad(5)$ & $0.0 \% \quad(0)$ \\
\hline Total & $100 \%(56)$ & $100 \%(14)$ & $100 \%(52)$ & $100 \%(11)$ \\
\hline
\end{tabular}

Data presented as $\%(n)$.

with the increased physical demands. Solomon and Micheli ${ }^{13}$ support this conclusion, stating that modern dance encompasses unique technical demands (e.g., parallel lower limbs, contraction, and relaxation) that differ from traditional dance, such as ballet.

The fewest injuries occurred in December (reported) and February (self-reported). Students are on holiday for a large proportion of December, which may account for the low number of reported injuries. There is no ascertained reason why there would be no self-reported injuries at all in February.

Knee injuries were the most common self-reported site, accounting for $21 \%$ of all self-reported injuries and $17 \%$ of reported injuries. Previous literature has found that knee injuries occurred more frequently in contemporary dance than in other genres. ${ }^{13}$ "Screwing the knees" to force turnout has been found to be a common occurrence in dance, and the literature has suggested that this maneuver puts strain on the ligaments and meniscus of the knee., ${ }^{2,11}$ However, Milan ${ }^{11}$ also stated that the majority of these problems in dancers were minor, and the present study found that of the 13 injuries occurring at the knee, only 3 were ligament or meniscal problems. This information was acquired from the self-reported data, as the knee information obtained through Injury Zone did not state exactly the type of injury.

Solomon and Micheli ${ }^{13}$ suggested that as the emphasis in contemporary dance is less on turnout, injuries might have different mechanisms. Other studies that have also found knee injuries as the most common injury attributed them to functional control of turnout, improper technique, floor work, repetitive loading, and overuse. ${ }^{6,11}$ The present study found that the most common perceived causes of injury were overuse and jumping, followed by challenging movements. This supported the findings that the most common risk of injury is jumping and this may be due to the stretch-shortening cycle ${ }^{19}$ (eccentric muscle contraction followed by concentric contraction), as occurs in jumping. It is possible that the injuries seen in the present study were caused by environmental factors, such as the floor surface or footwear, or by overuse injuries from the high frequency of classes in their new training regime for the course.
Differences were found between the results obtained by different methods used to report the injuries. For the selfreported data, the participants completed a questionnaire in June, in which they had to recall information from the previous year. Gabbe and colleagues ${ }^{20}$ found that the accuracy was $80 \%$ when dancers were asked to recall the number of injuries sustained in a 12-month period but declined to $61 \%$ when specific details were required. The results of the present study did show differences between the reported and selfreported number of injuries, which may be due to memory recall. It also may be that what a dancer perceives as an injury and an injury that requires professional attention differ. This was supported by only 63 injuries being reported compared to 70 self-reported, suggesting that the first-year dance students were more reluctant to visit the physiotherapist or were unable to recall injuries that occurred up to a year ago. ${ }^{20} \mathrm{In}$ general, the accuracy of self-reported injury data is questionable but allowed an important comparison to be made in the present study. The results of the present study highlight the need for clinicians to keep accurate and detailed notes. This, in turn, is important due to the reluctance of students reporting to the physiotherapist.

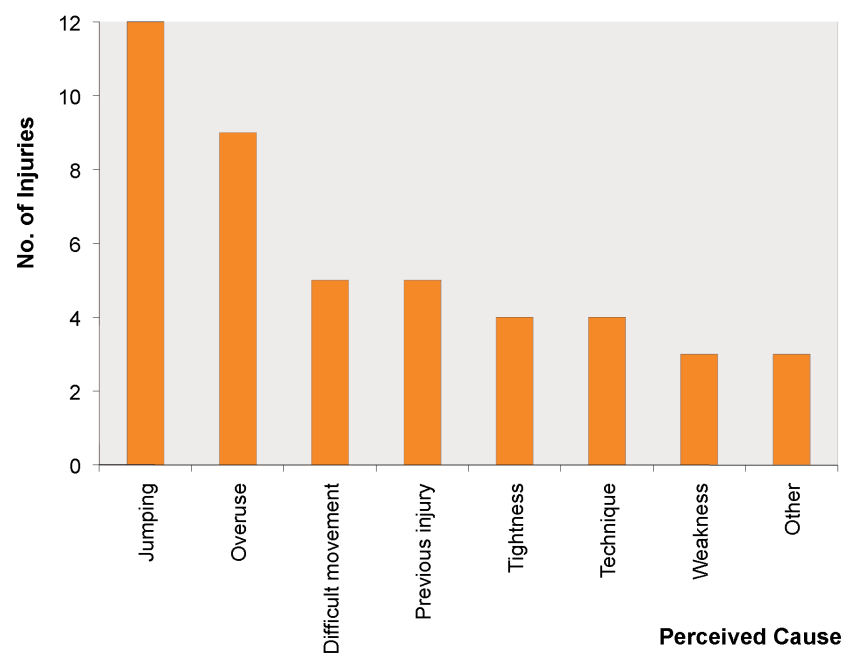

FIGURE 3. Self-reported perceived causes of injury sustained by male and female first-year contemporary dance students. 
Previous literature has suggested that dancers do not like to admit to clinical staff that they have an injury, through fear that it would be reported back to their teachers or choreographers ${ }^{21}$ and affect their future. Students may worry that if they are seen to be taking too much time out of class due to injury, it may affect their training, and the conservatoire in the present study enforces a policy that $80 \%$ of each module must be attended. If a student watches a class, due to injury, this counts as half an absence. Returning to dance too quickly or not reporting an injury can be detrimental to a dancer's health, and although the conservatoire's policy may be preparing dancers for the professional dance world, it could have long-term physical affects. This policy may require modification to ensure that the students do not feel pressure when injured. Perhaps identifying the cause of the problem and providing dance-specific rehabilitation would be more useful.

Of all of the injuries identified, lower-limb injuries accounted for $73 \%$ and $78.6 \%$ of reported and self-reported injuries, respectively. This concurred with previous literature that found $71.6 \%,{ }^{5} 65$ to $80 \%,{ }^{11}$ and $69.8 \%{ }^{13}$ incidence rates of the lower limb. Shin splints were the most common specific injury self-reported in the present study. Twenty percent of self-reported injuries were shin splints, compared to only $9.52 \%$ of reported. This suggested that shin injuries were often occurring in dancers but the dancers were reluctant to report these injuries to a clinician. However, the literature has suggested that hard floors, repetitive jumping, thin-soled or no shoes, and compensated turnout could also increase the likelihood of shin splints. ${ }^{8-9}$ Musculoskeletal injuries were found to decrease by $80 \%$ when floor surfaces were adapted to proper resilience. ${ }^{8}$ It is important to consider also that due to the high profile of shin splints in the dance world and literature, this would be the most obvious conclusion when self-diagnosing pain at the shin. Another reason for the large difference between reported and self-reported shin splint injuries may be because students thought that reporting shin splints was not important. However, stress fractures or traction fasciitis would present in the same way. ${ }^{?}$

In the self-reported results for male dancers, $21.4 \%$ of injuries $(n=3)$ were of the lower back, but the reported results showed only $9.1 \%$ ( 1 injury). The sparse number of male participants reduced the reliability of these results. The self-reported results found little difference between upper body injuries in males and females (12.5\% vs $14.3 \%$ ); however, the difference was greater in the reported results $(7.7 \%$ vs $36.4 \%)$. There is limited literature comparing injuries sustained by males and females, though previous studies have found males to incur more upper limb injuries than females ${ }^{5}$ due to the nature of their performance roles, i.e., lifting.

\section{Limitations and Indications for Future Research}

The Injury Zone software was in use by all clinical staff at the conservatoire, and diagnoses were subjective. It should also be considered that the month attributed to each injury in the reported data was when the dancer presented and not defi- nitely when the injury occurred. Injury Zone provides specific codes, which the therapist may have to fit to an injury that is not described exactly. Physiotherapists often have limited time and therefore do not provide full details for each injury. Injury Zone can be an excellent tool for collecting injury data; however, guidelines and training should be set up for clinicians to follow to improve consistency when evaluating the data collected. It is recommended that future research would assess the reliability of methods used to report injuries, from students individually, interviews, and clinicians' methods.

Another limitation of this study was the inability to distinguish whether the same injuries that were self-reported were also reported. It would have been useful to have observed what percentage of the reported injuries was also self-reported, and vice versa. In addition, it cannot be guaranteed that students would self-report injury details fully or accurately.

For this conservatoire, future research may include indepth evaluation of the incidence of shin splints and possible causes of the high number reported. It may be necessary to review the policy regarding absence due to injury to ensure that dancers receive treatment as and when it is required.

\section{CONCLUSION}

In summary, the incidence of injuries of first-year dance students at this conservatoire was high and may be due to the sudden increase in workload with full-time training. Dancers at this conservatoire did not report to the physiotherapist all injuries that they incurred, possibly due to the absence policy enforced. A reluctance to report injuries to a clinician may reduce the longevity of their dance careers. The cause of injuries is likely to be multifactorial, and further research should address this. The cause of injury in contemporary dance may differ from those in ballet due to the different demands of the genre, and this also should be addressed in the future.

\section{REFERENCES}

1. Conti SF, Wong YS: Foot and ankle injuries in the dancer. J Dance Med Sci 2001; 5(2):43-49.

2. Reid DC: Prevention of hip and knee injuries in ballet dancers. Sports Med 1988; 6:295-307.

3. Lawson J: The injury scene: dancers and footballers. The Dancing Times, 1989; (Sep):1122-1123.

4. Gordon S: Off Balance: The Real World of Ballet. New York: Pantheon Books; 1983.

5. Nilsson C, Leanderson J, Wykman A, Strender L: The injury panorama in a Swedish professional ballet company. Sports Traumatol 2001; 9:242-246.

6. Somogyi DM: Lower leg injuries in dance. J Dance Med Sci 2001; $5(1): 21-25$.

7. Washington EL: Musculoskeletal injuries in theatrical dancers: site, frequency and severity. Am J Sports Med 1978; 6(2):75-83.

8. Lawson J: The shin splints epidemic. The Dancing Times 1991; (Nov): 137 .

9. Coplan JA: Ballet dancer's turnout and its relationship to self-reported injury. J Orthop Sports Phys Ther 2002; 32(11):579-584.

10. Negus V, Hopper D, Briffa NK: Associations between turnout and lower extremity injuries in classical ballet dancers. J Orthop Sports Phys Ther 2005; 35(5):307-318. 
11. Milan KR: Injury in ballet: a review of relevant topics for the physical therapist. J Orthop Sports Phys Ther 1994; 19:121-129.

12. Byhring S, Bo K: Musculoskeletal injuries in the Norwegian National Ballet: a prospective cohort study. Scand J Med Sci Sports 2002; 12:365-370.

13. Solomon RL, Micheli LJ: Technique as a consideration in modern dance injuries. Phys Sportsmed 1986; 14(8):83-89.

14. Bauman PA, Singson R, Hamilton WG: Femoral neck anteversion in ballerinas. Clin Orthop 1994; 302:57-63.

15. Khan K, Brown J, Way S, et al: Overuse injuries in classical ballet. Sports Med 1995; 19(5):341-357.

16. Laws H: Fit to Dance 2. London: Dance UK; 2005.
17. Jenkinson DM, Bolin DJ: Knee overuse injuries in dance. J Dance Med Sci 2001; 5(1):16-20.

18. Definition of injury [webpage]. MSN Encarta, 2007. Available at: http://uk.encarta.msn.com/dictionary_1861791879/injury.html; accessed Aug 09, 2007.

19. Gabbe BJ, Finch CF, Bennell KL, Wajswelner H: How valid is a selfreported 12-month sports injury history? Br J Sports Med 2003; 37:545-547.

20. Scioscia TN, Giffin JR, Fu FH: Knee ligament and meniscal injuries in dancers. J Dance Med Sci 2001; 5(1):11-15.

21. Deighan MA: Flexibility in dance. J Dance Med Sci 2005; 9(1):13-16. 